\title{
TEMAS E CONTEÚDO DO JOGO DE PAPÉIS: Sinalizando Caminhos Para a Atuação Pedagógica com a Atividade Lúdica na Educação Infantil
}

\author{
Dóris de Jesus Moya ${ }^{1}$ \\ Marta Sueli de Faria Sforni ${ }^{2}$ \\ Paula Tamyris Moya ${ }^{3}$
}

\begin{abstract}
RESUMO
Para a Teoria Histórico-Cultural, a atividade lúdica é fundamental no desenvolvimento psíquico da criança. Para compreendermos as razões de se considerar essa atividade importante para o desenvolvimento infantil, realizamos uma pesquisa de caráter bibliográfico, na qual centramos nossa análise na produção de Leontiev e Elkonin, autores dessa linha teórica que se ocuparam do estudo do desenvolvimento psíquico e da periodização do desenvolvimento infantil. Elkonin afirma que o jogo de papéis é a atividade lúdica que maior impacto exerce no desenvolvimento de crianças na faixa etária que corresponde ao final da educação infantil. Ele distingue dois elementos no jogo de papéis: o tema e o conteúdo. Por meio da compreensão desses elementos é possível reconhecer que nas instituições educativas, além de se reservar tempo e espaço para esse tipo de atividade lúdica, é preciso atuar pedagogicamente no conteúdo dela. Essa atuação pedagógica sobre o conteúdo do jogo não é o mesmo que dirigir diretamente as ações da criança, privando-a da liberdade de criação, mas significa atuar de modo a propiciar condições para que as crianças ampliem seu universo cultural, favorecendo o acesso ao conhecimento de várias atividades humanas presentes na realidade objetiva, de modo a enriquecer suas possibilidades de imitação, imaginação e criação na brincadeira.
\end{abstract}

Palavras-chave: Jogo de papéis. Elkonin. Desenvolvimento psíquico. Teoria histórico-cultural. Educação infantil.

THEMES AND CONTENTS IN THE GAME OF ROLES:

SHOWING THE WAY FOR PEDAGOGICAL PRACTICE WITH LUDIC ACTIVITIES IN CHILDREN'S EDUCATION

\begin{abstract}
According to the Historical and Cultural Theory, playful activities are basic within children's psychic development. A bibliographic research was undertaken to understand the reasons why such activities are relevant for children's development. Our analysis focused on the production of the authors Leontiev and Elkonin who were engaged in the theory and study of children's psychic development and periodization. Elkonin states that the game of roles or the game of agents is the ludic activity with the greatest impact on children's development within the age bracket corresponding to the end of children's education. The author distinguishes two factors in the game of roles, namely, the theme and the content. When one understands these factors, one has to perceive that, besides concentrating on space and time for this type of ludic activity in educational institutes, its contents should be pedagogically worked out too. Pedagogical agency on the contents of the game is different from directly affecting children's activities. It rather means the establishment of conditions so that children broaden their cultural worldview by favoring access to knowledge on different human activities within objective reality. Consequently, the possibilities of imitating, imagining and creating would be enriched in the games.
\end{abstract}

Keywords: Game of roles. Game of agents. Elkonin. Psychic development. Historical and cultural theory. Children's education.

Recebido em: $13 / 2 / 2019$

Aceito em: $17 / 6 / 2019$

\footnotetext{
${ }_{1}^{1}$ Professora da Educação Básica. Doutoranda em Educação pela Universidade Estadual de Maringá (in memoriam).

${ }^{2}$ Mestre em Educação pela Universidade Estadual de Maringá. Doutora em Educação pela USP e pós-doutora em Educação pela Unicamp. Professora do Programa de Pós-Graduação em Educação da Universidade Estadual de Maringá. martasforni@uol.com.br

${ }^{3}$ Professora da Educação Básica no município de Cambira-PR. Professora na Faculdade de Apucarana (FAP) e doutoranda no Programa de Pós-Graduação em Educação da Universidade Estadual de Maringá. ptmoya17@hotmail.com
} 
A ludicidade é considerada parte do mundo infantil e, portanto, é contemplada no currículo da Educação Infantil, e em algumas escolas ainda se reserva um tempo para a atividade lúdica nos anos iniciais do Ensino Fundamental. Não raro, todavia, é uma atividade desenvolvida apenas com a finalidade de descontrair as crianças. Assim compreendidos, os jogos ${ }^{4}$ e as brincadeiras ${ }^{5}$ normalmente ocorrem sem a intervenção direta do professor e são realizados em momentos de pausa das atividades pedagógicas, ou seja, ganham espaço no contexto escolar quando as crianças estão cansadas das atividades que são consideradas, de fato, escolares, como aquelas relacionadas aos conteúdos curriculares clássicos. Quando a atividade lúdica assume esses contornos, constata-se que ela é vista como uma atividade alheia à aprendizagem e ao desenvolvimento infantil.

Em decorrência dessa compreensão, observa-se, no interior das escolas e dos centros de educação infantil, tempos e espaços reduzidos para a prática de jogos e brincadeiras, uma vez que eles são considerados menos produtivos em relação às outras atividades escolares. Por outro lado, a defesa da presença da atividade lúdica na educação das crianças não é nova. Esse discurso está presente nos cursos de formação inicial e continuada de professores, bem como nos documentos oficiais do Ministério da Educação, que orientam a Educação Infantil (BRASIL, 2006, 2009, 2017) e o primeiro ano do Ensino Fundamental de nove anos (BRASIL, 2007). Há, todavia, uma distância entre o enunciado no discurso e aquilo que os professores levam a termo em sala de aula.

Consideramos que uma das justificativas para esse fato está na falta de estudos aprofundados acerca das razões de a atividade lúdica ser um componente essencial no desenvolvimento psíquico infantil. Esses estudos permitiriam ao professor não se ater apenas ao discurso que prescreve o dever de contemplar a atividade lúdica em sua prática, mas, sobretudo, compreender teoricamente essa atividade, para, com base nesse conhecimento, tomar decisões sobre os modos mais adequados de desenvolvê-la em contexto escolar.

Com a intenção de contribuir para a compreensão da relação entre a atividade lúdica e o desenvolvimento infantil, realizamos uma pesquisa de caráter bibliográfico, fundamentada na Teoria Histórico-Cultural. A opção pelo estudo dos pressupostos desse referencial teórico decorreu do fato de que, nesta perspectiva, foram desenvolvidas pesquisas teóricas e de campo sobre esse tema, o que levou pesquisadores dessa linha a considerar os jogos e as brincadeiras atividades que promovem o desenvolvimento psicológico da criança, elegendo-as como atividades essenciais no processo educativo. De modo geral, discutimos até aqui sobre as contribuições da atividade lúdica, considerando os diversos tipos de jogos e brincadeiras, mas, para Elkonin (1998, p. 21), “O objeto de nossa pesquisa é a natureza e o conteúdo do jogo de papéis, a psicologia dessa forma evoluída da ativida-

\footnotetext{
${ }^{4}$ Para Elkonin (1998, p. 13), "A palavra 'jogo' não é um conceito científico stricto sensu". Assim, esse termo pode contemplar, por exemplo, o jogo com soldadinhos de chumbo, as representações dramáticas no teatro e até o jogo infantil com bola de gude, mas é importante destacar que o foco das investigações de Elkonin (1998) foi um tipo especial de jogo: o jogo de papéis, que representa a unidade fundamental do jogo das crianças que frequentam a pré-escola (ELKONIN, 1998)

${ }^{5}$ As brincadeiras e os jogos são considerados modalidades da atividade lúdica.
} 
de lúdica [...]". Com base na tese metodológica de Marx 6 , Elkonin (1998) definiu o jogo de papéis ou jogo protagonizado ${ }^{7}$ como a forma mais desenvolvida da atividade lúdica. Isso significa que, por meio do estudo dos elementos essenciais que constituem o jogo de papéis, é possível conhecer as múltiplas manifestações dessa atividade lúdica, bem como as suas contribuições para o desenvolvimento infantil. Sendo assim, apresentamos nos itens a seguir dois elementos essenciais que Elkonin (1998) distingue no jogo de papéis: o tema e o conteúdo.

\section{TEMAS DOS JOGOS DE PAPÉIS}

Segundo os autores da teoria Histórico-Cultural, os jogos e brincadeiras são atividades que proporcionam a apropriação de normas sociais e de conduta, estruturando a comunicação e o uso instrumental dos objetos elaborados pelos seres humanos ao longo do processo histórico da humanidade. Utilizando-se da ludicidade, a criança apropria-se do mundo concreto dos objetos humanos, por meio da reconstituição das ações que os adultos realizam com esses objetos.

Para Elkonin (1998), o jogo de papéis é a forma mais evoluída dos diferentes tipos de jogo, posto que, por meio dele, acontece a reconstituição pela criança da atividade social que ela busca representar. A preocupação de Elkonin (1998) está em compreender esse tipo de atividade com base na categoria trabalho, estabelecendo relação com as transformações na estrutura social. Elkonin (1998) assim concebe a atividade do jogo infantil:

Uma vez que a atividade concreta das pessoas e suas relações são variadíssimas na realidade, também os temas dos jogos são muito diversificados e cambiáveis. Nas diferentes épocas da história, segundo as condições sócio-históricas, geográficas e domésticas concretas da vida, as crianças praticam jogos de temática diversa. São diferentes os jogos das crianças de diferentes classes sociais, dos povos livres e dos povos oprimidos, dos povos nórdicos e dos povos meridionais, dos que habitam em regiões arborizadas ou desérticas, dos filhos de operários industriais, de pescadores, de criadores de gado ou de agricultores. Inclusive uma mesma criança muda os temas de seus jogos segundo as condições concretas em que se encontra temporariamente (ELKONIN, 1998, p. 34).

Nessa exposição de Elkonin, fica evidente que os temas do jogo de papéis das crianças não são todos iguais; eles se diferenciam em decorrência de três aspectos: a) localização geográfica; b) momento histórico e c) classe social em que a criança está inserida. A influência do aspecto geográfico pode ser sentida ao observamos, por exemplo, que é comum entre as crianças que vivem em regiões litorâneas brincar de pescador, surfista e turista, e que crianças que vivem em algumas regiões da Amazônia tendem a brincar de caçador, índio e animal.

\footnotetext{
${ }^{6}$ Para Marx (1978, p. 120), "A anatomia do homem é chave da anatomia do macaco", isto é: para a compreensão das formas inferiores de um fenômeno ou objeto é preciso ter como ponto de partida a sua forma mais desenvolvida, que contempla as múltiplas relações que determinam o fenômeno ou objeto investigado.

7 Elkonin (1998), em sua obra "A Psicologia do Jogo", utiliza o termo jogo protagonizado como sinônimo de jogo de papéis, mas no presente texto optamos por adotar apenas o termo jogo de papéis para garantir a compreensão do leitor.
} 
O aspecto histórico, citado por Elkonin (1998), lança luzes sobre a diferença dos temas dos jogos de papéis em distintos momentos históricos, mesmo que se considere o mesmo espaço geográfico. Os jogos de papéis das crianças de uma mesma região são diferentes de acordo com o período histórico em que elas vivem. Por exemplo, uma criança do Rio de Janeiro do Período Imperial possivelmente faziam atividades lúdicas bastante diferentes das que realizam hoje as crianças que vivem nesse mesmo local.

Também pode ser facilmente identificada a influência das diferenças de classe social nos temas dos jogos das crianças, como aponta Elkonin (1998). São diferentes, por exemplo, os temas dos jogos de papéis dos filhos dos operários e os dos filhos de empresários.

Se, no entanto, há tantas diferenças entre jogos de papéis, é possível a existência de uma teoria geral do jogo? É possível a existência de algo que dê unidade a esse tipo de jogo, independentemente das diferenças geradas pelas condições históricas, geográficas e sociais?

Em primeiro lugar, a compreensão dessas diferenças não torna o jogo de papéis tão relativo que impeça qualquer movimento de generalização teórica sobre o tema, e não nega a possibilidade de uma teoria geral sobre esse jogo; pelo contrário, foi essa constatação que permitiu a Elkonin lançar um pressuposto básico de sua teoria: “[...] os temas dos jogos dependem das condições concretas em que se encontra temporariamente [a criança]" (ELKONIN, 1998, p. 35). A existência de diferenças na atividade lúdica da criança em distintos tempos, espaços e classe social, demonstra que as condições materiais são determinantes nos temas do jogo de papéis.

Elkonin não para sua análise nesse ponto; ele percebe que, apesar das grandes diferenças já descritas, há algo que unifica o jogo de papéis, o que permite responder afirmativamente à pergunta sobre a possibilidade de existência de algo que dê unidade a esses jogos infantis.

[...] o singular impacto que a esfera da atividade humana e das relações entre as pessoas produz no jogo evidencia que, apesar da variedade dos temas, todos contêm, por princípio, o mesmo conteúdo, ou seja, a atividade do homem e as relações sociais entre as pessoas (ELKONIN, 1998, p. 35, grifos nossos).

Nessa explicação de Elkonin, cabe enfatizar duas palavras: tema e conteúdo. O autor alerta para o fato de que o que se diferencia é o tema do jogo de papéis. Há, porém, algo comum a todos esses jogos, ou seja, independentemente das diferenças históricas, geográficas ou de classes, o conteúdo é o mesmo. Qual é esse conteúdo que unifica todos os diferentes temas dos jogos de papéis?

\section{CONTEÚDO DOS JOGOS DE PAPÉIS}

Elkonin (1998) chama atenção para o fato de que o que muda no jogo infantil é o seu tema, não o seu conteúdo. O tema do jogo significa o assunto que será reconstituído pela criança, e o conteúdo é o aspecto central. Ele gira sempre em torno da "[...] a atividade do homem e as relações sociais entre as pessoas" (ELKONIN, 1998, p. 35), independentemente da variação do tema que a criança venha a recompor. 
Ao descrever a relação entre o jogo de papéis e as condições concretas da vida da criança, Elkonin deixa mais claro porque esse tipo de jogo está vinculado diretamente às relações das pessoas e não à percepção dos objetos. O modo de operar com os objetos não aparece inscrito nos próprios objetos; ele é efetivado nas ações humanas, como sugere Elkonin (1998, p. 35): na "atividade do homem". Não basta à criança ver o objeto; ela precisa vivenciar o adulto interagindo com ele. Por exemplo: nos primeiros meses de vida da criança é o adulto que segura a sua mamadeira; com o passar dos tempos ela começa a apalpá-la e, em seguida, passa a segurá-la sozinha, reproduzindo os mesmos gestos observados.

Nesse exemplo, percebe-se que a criança vai, paulatinamente, desenvolvendo a consciência do significado das atividades desenvolvidas pelos adultos, apropriando-se do conhecimento, da cultura, e, enfim, do meio em que ela vive, no sentido amplo que abrange o universo da atividade humana.

A criança, com a ajuda do adulto, não somente aprende a conhecer os aspectos exteriores da ação que ela busca imitar, mas também aprende a importância e o significado social que tem a atividade que ela imita, a atitude dos adultos para com ela e o modo como se organizam suas atividades. Para Vygotsky (1996), a imitação não significa a simples transferência direta e mecânica da conduta de um sujeito para o outro, pois "a imitação, se concebida em sentido mais amplo, é a forma principal em que se realiza a influência da aprendizagem sobre o desenvolvimento" (VYGOTSKY, 1996, p. 331). Para, todavia, a imitação exercer tal influência, é preciso que o sujeito compreenda o significado da ação do outro. Por essa razão, se no jogo de papéis evidencia-se o caráter concreto das relações existentes na realidade objetiva, nele não se faz presente apenas as relações da criança com os objetos, mas também a qualidade das relações interpessoais. Nas condições concretas em que a criança vive na sociedade capitalista, todos os conflitos de classe que marcam as relações entre as pessoas podem se manifestar no jogo de papéis.

[...]. Essas relações podem ser de cooperação, de ajuda mútua, de divisão de trabaIho e de solicitude e atenção de uns com os outros; mas também podem ser relações de autoritarismo, até de despotismo, hostilidade, rudeza, etc. Tudo depende das condições sociais concretas em que vive a criança (ELKONIN, 1998, p. 35).

Elkonin (1998) cita um experimento realizado por Zhukóvskaia, no qual ficou patente a ideia segundo a qual o conteúdo que move a ação lúdica é a reprodução da atividade humana. Ao estudar a influência dos jogos didáticos sobre os jogos independentes das crianças, a educadora promoveu uma visita dos alunos a uma loja, com o objetivo de identificar o que motivava os alunos a realizar seus jogos de papéis.

Unicamente as que descrevem de forma compreensível a atividade, o comportamento e as relações mútuas das pessoas despertam nas crianças o desejo de reconstituir em jogos o conteúdo fundamental dessas obras (MÁRKOVA apud ELKONIN, 1998, p. 31). 
No caso de apresentações de narrativas, via obras literária, para estimular a atividade lúdica na criança, o conteúdo presente nas tarefas, no comportamento e nas relações sociais dos personagens da obra, deve estar bem-definido e evidente para que a criança tenha interesse e vontade de desenvolver os seus jogos de papéis, reconstituindo as ações de cada personagem.

Desse modo, os personagens da obra literária produzida para o público infantil podem ser os modelos da ação para a criança. Esses personagens são tomados pela criança como espelhos, são seus heróis, despertam-lhes o sentimento de admiração e criam-Ihes motivos para desempenhar suas ações; no jogo de papéis, a criança imita seu trabalho, sua profissão e situações nas quais desenvolve suas ações.

Elkonin (1998) pondera que por esse motivo deve haver adequação e cuidados no uso dos livros de literatura, como também dos livros didáticos. Se esses não mostrarem com clareza as ações das pessoas, as crianças tendem a não desenvolver os seus jogos de papéis.

Ainda buscando evidências de que é a atividade humana que influi no jogo de papéis, e de que o conteúdo do papel assumido pela criança é o de reconstituição desse aspecto da realidade, Elkonin (1998) cita o exemplo de uma atividade realizada por uma educadora com crianças em idade pré-escolar. Ela levou os alunos a um jardim zoológico. No primeiro momento, a educadora solicitou às crianças que observassem os animais: como eles se alimentavam, se eram bravos ou mansos, enfim, como se comportavam. Ao retornarem à sala de aula, a educadora distribuiu aos alunos brinquedos idênticos aos animais que estavam no zoológico. No entendimento da educadora, a presença dos mesmos objetos pertencentes ao zoológico seria suficiente para as crianças começarem a desenvolver o jogo; mas não foi. A educadora, na certeza de que os alunos iniciariam as suas brincadeiras, propôs o mesmo encaminhamento por vários dias, e o resultado foi o mesmo: eles não demonstraram interesse pela tarefa.

Novamente a educadora levou os alunos até o zoológico e propôs uma nova situação de ensino. Ela dirigiu a atenção dos alunos para as atividades das pessoas. Por exemplo, como elas cuidavam dos animais e preparavam os alimentos, as atividades do zelador, do porteiro, do vendedor, do bilheteiro, enfim, fez com que o foco da atenção das crianças fosse as relações e os vínculos mais diversos que as pessoas que trabalhavam no zoológico estabeleciam entre si e com os animais. Com esse encaminhamento, as crianças demonstraram grande interesse e começaram a desenvolver suas brincadeiras de modo independente: passaram a reproduzir, por meio do jogo de papéis, como as pessoas cuidavam dos animais, o seu trabalho, as normas, as atitudes dos visitantes, e realizaram, por vários dias, a mesma atividade lúdica, tornando-a cada vez mais rica.

Com base na análise dessa experiência, Elkonin (1998) torna mais clara a tese, anteriormente citada, de que as condições concretas determinam o tema e o conteúdo do jogo, ou seja, o jogo está ligado à realidade da criança. Esse é um fato amplamente aceito nos atuais discursos educacionais sobre a atividade lúdica. Elkonin, porém, vai além dessa constatação. Ao analisar a experiência do zoológico, ele julga necessário qualificar melhor essa realidade, e distingue nela duas esferas - a esfera dos objetos e a esfera de atividade das pessoas. Essas duas esferas da realidade, para Elkonin (1998, p. 32), "influem de modo diferente no surgimento do jogo protagonizado". O autor indaga: Qual 
é essa diferença? Qual dessas duas esferas influi mais no jogo de papéis? As respostas para essas perguntas são fundamentais para se pensar em situações capazes de garantir a promoção do jogo de papéis no contexto escolar.

Na busca das respostas a essas questões, foi necessária a realização de outro experimento, esse conduzido por Koroliova sob a direção de Boguslávskaia. Organizou-se uma atividade cujo conteúdo foi a esfera objetiva da realidade - os objetos e as coisas - e uma cujo conteúdo fundamental constituiu-se da atividade dos homens e das relações entre as pessoas.

Para a realização do experimento foi organizada uma viagem de trem com as crianças. Na estação, elas observaram as pessoas subindo e descendo dos vagões. Elas também praticaram as mesmas ações, e compraram a passagem com seus pais, ouvindo o apito do trem na estação. As crianças sentiram-se emocionadas com o que vivenciaram tanto na estação quanto durante a viagem. Em outro momento, já na escola, a educadora, certa do desenvolvimento do jogo, colocou à disposição das crianças vários objetos, tais como locomotiva, carros e guichê. Apesar do grande envolvimento emocional que as crianças demonstram ter sentido durante a viagem, o contato com objetos similares aos vivenciados na viagem não propiciou o desenvolvimento do jogo de papéis entre elas. A educadora propôs outro experimento: levou as crianças novamente à estação e solicitou-lhes que observassem os objetos que estavam no local; mas essa situação de ensino também não influenciou o jogo de papéis das crianças, apenas melhorou a percepção que elas tinham dos objetos, o que pode ser verificado pelos desenhos que elas fizeram posteriormente.

No último experimento, a educadora repetiu a mesma viagem, mas a sua condução foi diferente das experiências anteriores. Ela solicitou que os alunos verificassem como o chefe da estação recebia cada trem, como os passageiros embarcavam, desembarcavam e compravam suas passagens, quais eram as ações e relações do maquinista, do cobrador, do responsável pela limpeza, etc. Nesse experimento, a ação da educadora estava em conduzir a atenção das crianças para outro foco: as observações das crianças concentraram-se nas atividades e nas relações entre as pessoas que estavam na estação ferroviária. Por meio dessa organização do ensino, posteriormente as crianças começaram a realizar seus jogos de papéis com o tema em pauta e envolveram-se na atividade por muito tempo.

Elkonin (1998) analisou outros experimentos semelhantes realizados por Koroliova; as crianças visitaram duas vezes uma oficina de costura, uma casa em construção, uma fábrica de jogos e o os correios, enfatizando, na primeira visita, a esfera dos objetos (objetos e as coisas), e, na segunda, as pessoas, suas atividades e as relações entre elas, ou seja, a esfera da atividade humana, do seu trabalho e as ações que realizavam. Os dados dos experimentos de Koroliova (1957), citados por Elkonin (1998), demonstram que a esfera da atividade e as relações entre as pessoas é o elemento fundamental do jogo protagonizado.

A resposta à indagação de Elkonin estava dada: é a realidade da criança que influencia a sua atividade lúdica; porém nem todos os aspectos dessa realidade, mas, sobretudo, aquela esfera ligada à atividade e às relações humanas. O simples contato com os objetos e as coisas não é suficiente para desencadear o jogo protagonizado na criança. Eis a síntese feita por Elkonin após analisar essas experiências: 
[...] a base do jogo protagonizado em forma evoluída não é o objeto, nem seu uso, nem a mudança de objeto que o homem possa fazer, mas as relações que as pessoas estabelecem mediante as suas ações com os objetos; não é a relação homem - objeto, mas a relação homem - homem. E como a reconstituição e, por essa razão, a assimilação dessas relações transcorrem mediante o papel de adulto assumido pela criança, são precisamente o papel e as ações organicamente ligadas a ele que constituem a unidade do jogo (1998, p. 34).

A constatação feita por Elkonin (1998) e demais pesquisadores lança luzes sobre a forma de condução do jogo de papéis na escola. Embora, normalmente, o professor defenda o brincar como uma prática importante para o desenvolvimento cognitivo das crianças, não raro a única ação docente realizada é a de disponibilizar brinquedos e objetos para que a criança brinque. Da teoria de Elkonin (1998) sobre o jogo de papéis, entretanto, pode-se depreender que essa situação somente pode ser rica para o desenvolvimento psíquico infantil se também forem organizadas situações nas quais as crianças observem e interajam com atividades diversificadas do mundo adulto, de modo que possam transferir para a atividade lúdica as ações e os conteúdos observados. Assim, as crianças teriam condições efetivas para o desenvolvimento da imaginação e abstração, tal como exposto por Vygotsky (2007).

É importante que se busque a superação dessa forma de pensar e organizar o jogo de papéis das crianças. Quando o brincar das crianças é realizado sem a mediação do adulto para fins exclusivos de diversão ou entretenimento, tem-se uma prática fundada no espontaneísmo, enfatizando o caráter livre e desconsiderando as potencialidades formativas presentes nesse tipo de jogo. Essa prática não exerce todo o potencial que poderia exercer sobre o desenvolvimento das funções psicológicas superiores da criança.

Estudos dessa natureza também foram contemplados por Jukovskaia (1978), o qual assinala que a criança somente reproduz o jogo de papéis de maneira criativa quando ela conhece o que representa. Ao considerar somente a própria experiência, no entanto, a percepção da criança torna-se superficial e dispersa. As fontes que influenciam de modo positivo o conteúdo do jogo de papéis é a experiência direta da criança, adquirida na prática organizada pelo professor. Por isso, o jogo de papéis não se desenvolve movido por manifestações biológicas, ou seja, pelos instintos da criança. Para comprovar essa tese, o autor cita como exemplo um experimento no qual crianças em idade pré-escolar visitaram uma granja de aves. Jukovskaia relata e analisa o resultado desse experimento:

Ao analisar conjuntamente com a educadora a conduta dos grupos pré-escolares, chegamos à conclusão de que a forma em que se desenvolveu o jogo não contribuiu para a correta educação da criança, porém a educadora se esforçou para as crianças jogarem de forma amistosa e ajudou cada um deles. Como se explica o resultado obtido no jogo?

Antes de tudo se explica porque durante os passeios e a visita à granja de aves e durante as conversas, a educadora não chamou a atenção das crianças sobre a atmosfera amistosa que reinava na atividade das pessoas que trabalhavam. 
As relações entre eles não motivaram as crianças. Por isso, no jogo deles não se refletiu os aspectos positivos do trabalho de seus pais na granja de aves ${ }^{8}(1978, p$. 78-79, tradução nossa).

Mesmo contando com a observação, participação e ajuda do professor, as crianças não desempenharam os papéis esperados, ou seja, elas não sentiram interesse para reconstituir as atividades das pessoas, e, portanto, o jogo de papéis não se desenvolveu. O professor não dirigiu a atenção das crianças para as ações e atividades das pessoas que trabalhavam no local, por isso o resultado foi insatisfatório, conclui o autor.

Fenômeno semelhante é relatado por Marega e Sforni (2011). Por meio de um experimento didático, as autoras criaram três momentos que colocavam a criança em interação com objetos/brinquedos que poderiam ser utilizados no jogo de papéis. Em um primeiro momento, somente foram disponibilizados brinquedos de meios de transporte; no segundo momento foi sugerido às crianças que brincassem de motoristas e passageiros, utilizando-se dos brinquedos. Essas duas formas de intervenção do adulto não foram suficientes para que as crianças brincassem e, mesmo aquelas que buscavam interagir com os objetos, não se mantinham nessa ação por muito tempo. A situação modificou-se, surgindo a atividade lúdica, quando, escolhido um meio de transporte - o avião -, orientou-se a atenção das crianças para as relações pessoais existentes nessa forma de transporte: piloto, comissários de bordo e passageiros. Essas relações começaram a ser imitadas pelas crianças.

Em outra pesquisa, Ottoni e Sforni (2019), ao procurarem compreender como organizar o ensino de conceitos científicos na educação infantil, durante a realização de um experimento em um centro de educação infantil, também evidenciaram a diferença na qualidade das brincadeiras das crianças quando elas dispunham apenas de brinquedos de animais presentes em sala de aula e após uma visita a uma fazenda, em que puderam ter contato com animais e conhecer as várias ações das pessoas que cuidavam deles.

Como afirmado anteriormente, não basta o professor observar, participar e oferecer diversos brinquedos para que as crianças desenvolvam os papéis, pois o jogo não acontece espontaneamente. A principal influência no jogo de papéis das crianças é a atenção sobre a atividade das pessoas, as ações dos adultos. Se o conteúdo que exerce maior influência no desenvolvimento do jogo de papéis pelas crianças são as ações e as atividades das pessoas, o papel do professor não está apenas em oportunizar momentos e objetos para essas atividades, mas em propiciar condições para que os alunos tenham ricos conteúdos para a sua atividade lúdica. Elkonin pontua que o conteúdo é sempre a atividade humana:

\footnotetext{
${ }^{8} \mathrm{Al}$ analizar conjuntamente con la educadora la conducta de este grupo de prescolares, llegamos a la conclusión de que la forma en que se desarrolló el juego no contribuyó a la correcta educación de los niños, aunque la educadora se esforzó por que los niños jugaran de forma amistosa y ayudó a cada uno de ellos a desempeñar su papel. ¿Cómo se explica el resultado obtenido del juegoc
} 
[...] A especial sensibilidade do jogo na esfera da atividade humana e as relações entre os homens, mostra que apesar de toda a variedade de temas, o conteúdo é sempre o mesmo: a atividade humana e as relações dos homens na sociedade" ${ }^{\prime 9}$ (1986, p. 77, tradução nossa).

Esse mesmo entendimento está presente nos estudos de Jukovskaia (1978). Ele cita como exemplo uma situação de ensino desenvolvida com um grupo de crianças. Durante uma excursão, elas tiveram a oportunidade de observar todo o processo de construção de uma casa. O mestre de obra explicou e mostrou as ações das pessoas que trabalhavam no local da obra, ou seja, as crianças verificavam as atividades do pedreiro e do ajudante do carpinteiro, como os veículos transportavam o material de construção e o preparo do material, enfim, todas as atividades das pessoas envolvidas no trabalho de construção da casa. Esse encaminhamento motivou o desenvolvimento do jogo de papéis, quando as crianças reconstituíram as atividades das pessoas que trabalhavam na obra. Conforme o autor, o jogo de papéis desenvolveu-se de maneira criativa, porque o professor direcionou o interesse da criança para o trabalho dos adultos. Elas observaram as ações e as atividades das pessoas mais experientes.

O processo de constituição e desenvolvimento da brincadeira é resultante da prática e das ações dos adultos que circundam a criança. Sendo assim, a atividade lúdica, dentre elas o jogo de papéis, não ocorre somente porque a criança gosta de brincar ou porque essa atividade é prazerosa e divertida; ela provém, sobretudo, da necessidade que a criança tem de agir no mundo real. Esse fato aponta para uma questão central: as pessoas que interagem diretamente com a criança são criadoras de modelos. Assim, no jogo de papéis o professor desempenha uma função preponderante; ele é o mediador responsável por definir os conteúdos e o modo de inserir as crianças nesses conteúdos, disponibilizando os objetos/brinquedos. Além disso, o docente é responsável por organizar ações capazes de mobilizar as crianças envolvendo-as na atividade humana representada no jogo de papéis, isto é, nas relações sociais e nos modos de operar com os objetos.

A realidade da criança está dividida em dois mundos. "O mundo dos objetos" e o "mundo das pessoas" e, nesse sentido, buscou a natureza do jogo de papéis em crianças em idade pré-escolar para tratar desta questão. Este tipo de jogo é sensível ao "mundo das pessoas", porque modelam as tarefas e os motivos da atividade humana e as normas das relações entre as pessoas. $O$ jogo de papéis é uma atividade social, pois seu conteúdo é social posto sob as relações travadas pelas crianças com os adultos (LARA, 2000, p. 117).

Reiteramos que no jogo de papéis as condições mais importantes e necessárias para promover as mudanças no desenvolvimento psíquico da criança encontram-se no círculo das relações sociais, na interação que a criança estabelece com as pessoas mais experientes. Nesse âmbito, é essencialmente da apropriação da cultura que surgem as possibilidades do desenvolvimento dos sujeitos. Como sugere Rocha, "[...] desenvolver-se como ser humano significa apropriar-se dos instrumentos que a cultura produziu

\footnotetext{
${ }^{9}$ La especial sensibilidad del juego a la esfera de la actividad humana y a las relaciones entre los hombres, muestra que a pesar de toda la variedad de argumentos, trás estos se encuentra de los hombres en la sociedad. 
e produz, e dominá-los em sua dimensão humana, no que se refere a seu uso, historicamente definido" (ROCHA, 2005, p. 31). Na infância, o jogo de papéis é o modo mais efetivo para realizar essa apropriação.

Também Leontiev (1978) considera que a motivação primordial da criança no jogo de papéis é agir como as pessoas mais experientes. Esse é o maior motivo de passagem da ação com os objetos para o jogo de papéis.

[...] o mundo dos objetos que a criança assimila vai ficando cada vez mais vasto para ela. Nesse mundo já entram não só objetos que constituem o meio mais próximo da criança, objetos que ela própria pode manipular e manipula, mas também outros, de ação dos adultos, com os quais a criança ainda não pode operar na realidade e não estão ao seu alcance físico.

Portanto, a transformação do jogo na transição do período da mais tenra infância para a idade pré-escolar baseia-se na ampliação do círculo dos objetos humanos cuja assimilação se nos apresenta como uma tarefa e cujo mundo chegam a conhecer no transcurso do seu desenvolvimento psíquico (LEONTIEV apud ELKONIN, 1998, p. 402).

O jogo de papéis passa a ter uma função mediadora entre os desejos da criança de atuar no mundo dos adultos e a sua limitação em realizar esse desejo no plano real. "[...] É pela força dessa sensação que se explica a facilidade com que as crianças assumem os papéis dos adultos" (ELKONIN,1998, p. 404).

Para imitar as ações dos adultos, a criança imagina situações, observa atentamente seus modos de agir e os objetos utilizados por eles, e estabelece relações de raciocínio entre as ações empreendidas, enfim, mobiliza funções psíquicas como a imaginação, a atenção voluntária, a percepção e o pensamento. Ao mobilizar essas funções, são postas as condições para o seu desenvolvimento. Assim sendo, Elkonin (1998) ressalta que nenhuma atividade, nessa faixa etária, exerce tanta influência no desenvolvimento psíquico da criança quanto o jogo de papéis.

Também, o desenvolvimento dos sentimentos e da personalidade está ligado a um aspecto do jogo de papéis: o da evolução da conduta arbitrada. Trata-se das mudanças que ocorrem na conduta da criança perante esse jogo, em que ela precisa renunciar a desejos momentâneos para poder interpretar o papel que assumiu. Isso acontece em razão das regras que aparecem na situação lúdica: "[...] A regra está presente em todo jogo protagonizado, pois está implícita no papel a ser desempenhado pelas crianças" (ELKONIN, 1998, p. 417). Para o cumprimento das regras, as crianças mobilizam a atenção e a concentração. Ao exercer os papéis do mundo adulto, a criança tem normas para cumprir, dirige a atenção e concentra-se nas atividades e nas ações dos adultos. Por conseguinte, por meio do jogo de papéis, as crianças desenvolvem-se e inserem-se no mundo, como pontua Lara: "[...] para as crianças, é o brincar uma das instâncias em que produz a consciência do real" (2000, p. 65).

\section{CONSIDERAÇÕES FINAIS}

Autores da Teoria Histórico-Cultural defendem que é por meio da interação com os objetos, brinquedos e com diversas atividades sociais, que a criança, desde pequena, entra em contato com a cultura humana. Nesta perspectiva, o jogo de papéis é uma 
forma de aprendizagem, fruto das relações entre a criança e as pessoas mais experientes. Nesse tipo de atividade lúdica são estabelecidas relações que auxiliam a criança na compreensão do mundo, que vai ocorrendo por meio da apropriação da cultura.

Desse modo, não se pode correr o risco de que a presença das crianças em instituições de educação infantil represente um modo de escolarização que as prive de um elemento fundamental ao seu desenvolvimento, como demonstra Elkonin (1998), os direitos específicos de sua idade: o seu tempo e o espaço do brincar.

Não basta, todavia, o tempo e o espaço para brincar. É preciso atenção também para o conteúdo dos jogos de papéis. Se as crianças têm na atividade humana o conteúdo para esse tipo de jogo infantil, propiciar a elas o conhecimento de vários tipos de atividades é um meio de enriquecê-los. Nos experimentos citados ao longo deste texto observamos que as visitas orientadas à observação da atividade humana - no zoológico, na estação de trem, na construção civil - propiciavam mudanças qualitativas nas brincadeiras das crianças.

Visitas não são o único modo de ampliar o conhecimento das crianças sobre a atividade humana; literatura e filmes também podem cumprir essa função, desde que, tal como nas visitas relatadas, o professor medeie a relação das crianças com esses materiais, dirigindo a atenção delas para a atividade humana ali presente.

Não se trata de interferir diretamente na brincadeira da criança, definindo do que e como ela deve brincar, mas de propiciar o seu enriquecimento cultural para que o conteúdo de suas brincadeiras não fique restrito às atividades humanas mais imediatas ou àqueles modelos de ação que são apresentados pela mídia.

\section{REFERÊNCIAS}

BRASIL. Ministério da Educação. Ensino Fundamental de nove anos: orientações para a inclusão da criança de seis anos de idade. In: BEAUCHAMP, Jeanete; PAGEL, Sandra Denise.; NASCIMENTO, Aricélia Ribeiro do (org). Indagações sobre currículo - diversidade e currículo. Brasília, DF: MEC, 2007.

BRASIL. Ministério da Educação. Secretaria de Educação Básica. Parâmetros Nacionais de Qualidade para a Educação Infantil. Brasília, DF: MEC, 2006.

BRASIL. Ministério da Educação. Diretrizes Nacionais para a Educação Infantil. Brasília, DF: MEC, 2009.

BRASIL. Ministério da Educação. Base Nacional Comum Curricular. Brasília, DF: MEC, 2017.

ELKONIN, Daniil Borisovich. A psicologia do jogo. São Paulo: Martins Fontes, 1998.

ELKONIN, Daniil Borisovich. Antología de la Psicología Pedagógica y de las edades: La unidad fundamental de la forma desarrollada de la actividade lúdica. La naturaleza social del juego de roles. Moscou: Pueblo y Educación, 1986.

LARA, Ângela Mara de Barros. Pode brincar na escola? Algumas respostas da Educação Infantil. 2000. Tese (Doutorado em Educação) - Universidade Estadual Paulista, Marília, 2000.

JUKOVSKAIA, R. I. La educación del niño en el juego. Havana: Editorial Pueblo Y Educación, 1978.

LEONTIEV, Alexis N. O desenvolvimento do psiquismo na criança. In: LEONTIEV, Alexis N. O desenvolvimento do psiquismo. Lisboa: Livros Horizonte, 1978. p. 285-313.

LEONTIEV, Alexis N. Os princípios psicológicos da brincadeira pré-escolar. In: VIGOTSKI, Lev Semyonovich; LURIA, Alexander Romanovich; LEONTIEV, Alex N. Linguagem, desenvolvimento e aprendizagem. Trad. Maria da Penha Villalobos. São Paulo: Ícone; Edusp, 1988. p. 119-142.

MARX, Karl. Para a crítica da economia política. São Paulo: Abril Cultural, 1978.

MAREGA, Agatha Marine Pontes; SFORNI, Marta Sueli de Faria Sforni. A criança de seis anos na escola: É hora de brincar ou de estudar? Revista Contrapontos, v. 11, n. 2, p. 143-151, maio/ago. 2011.

OTTONI, Terezinha de Paula Machado Esteves; SFORNI, Marta Sueli de Faria Sforni. Aprendizagem conceitual na educação pré-escolar. Curitiba: Appris, 2019. 


\section{Rouista \\ \&Educaçã̃o}

Temas e Conteúdo do Jogo de Papéis:

sinalizando caminhos para a atuação pedagógica com a atividade lúdica na educação infantil

ROCHA, Maria Sílvia Pinto de Moura Librandi. Não brinco mais: a (des)construção do brincar no cotidiano escolar. 2. ed. Ijuí: Ed. Unijuí, 2005.

VYGOTSKY, Lev Semyonovich. A formação social da mente. São Paulo: Martins Fontes, 2007.

VYGOTSKY, Lev Semyonovich. Obras escogidas. Tomo IV. Tradução Lydia Kuper. Madrid: Visor Distribuidores, 1996. 